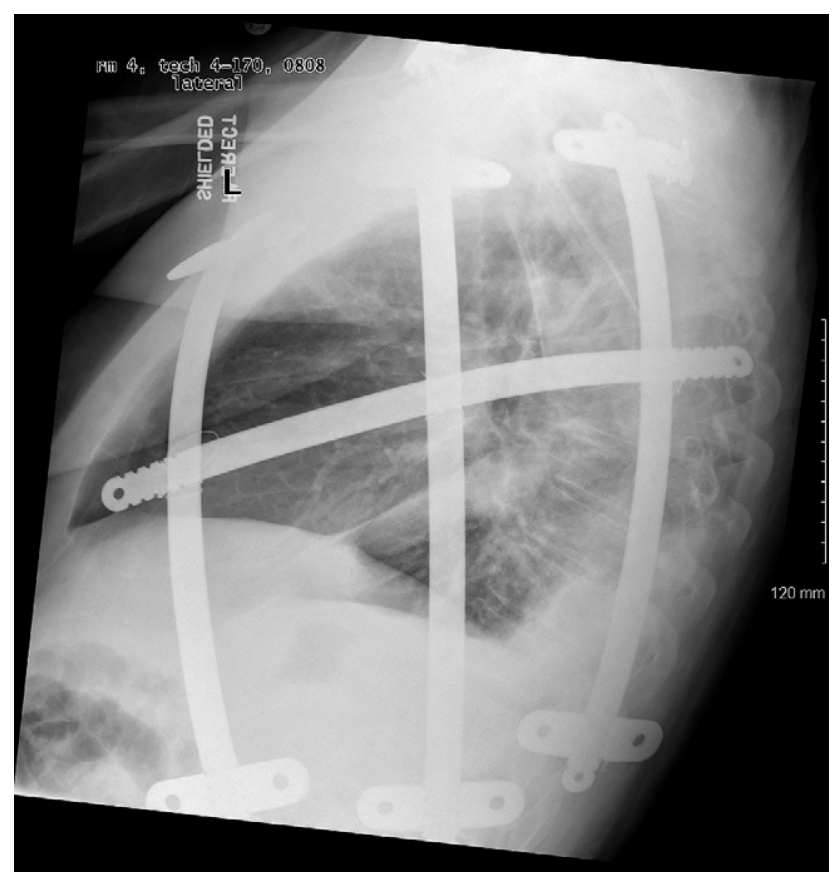

FIGURE 2. Lateral chest radiograph showing lung re-expansion and Nuss bar relationship in the final chest wall construct.

methylmethacrylate and osteosynthesis plates to stabilize a rib segment to an intact portion of the same or adjacent ribs. ${ }^{4,5}$ Our patient's injuries precluded other described techniques owing to the lack of intact structures to anchor stabilizing components. Our novel use of Nuss bars enabled us to create a viable superstructure to suspend the chest wall and allow full re-expansion of the lung. This technique will be useful in patients whose severity of injury precludes stabilization by previously described methods.

We corresponded with Dr Donald Nuss for his thoughts. He wrote:

This is a very novel and effective method of chest stabilization, which rescued a critically ill patient. A question that arises is whether the bars need to be removed after the patient has fully recovered. They may never require removal, but if the patient becomes symptomatic it will be somewhat of a challenge to remove them as they have stabilizers on each end. The use of absorbable sutures was a very good idea, and if the situation arises again I would recommend using absorbable stabilizers on each end so that after 6 months the bars can be extracted through small incisions.

We appreciate Dr Nuss' comments and will incorporate his suggestion in the future.

We thank Dr Donald Nuss for his review and comments.

\section{References}

1. Pettiford BL, Luketich JD, Landreneau RJ. The management of flail chest. Thorac Surg Clin. 2007;17:25-33.

2. Voggenreiter G, Neudeck F, Aufmkolk M, Obertacke U, Schmit-Neuerburg K. Operative chest wall stabilization in flail chest—outcomes of patients with or without pulmonary contusion. J Am Coll Surg. 1998;187:130-8.

3. Tanaka H, Yukioka T, Yamaguti Y, Shimizu S, Goto H, Matsuda H, et al. Surgical stabilization or internal pneumatic stabilization? A prospective randomized study of management of severe flail chest patients. J Trauma. 2002;52:727-32.

4. Bibas BJ, Bibas RA. Operative stabilization of flail chest using a prosthetic mesh and methylmethacrylate. Eur J Cardiothorac Surg. 2006;29:1064-6.

5. Engel C, Krieg JC, Madey SM, Long WB, Bottlang M. Operative chest wall fixation with osteosynthesis plates. J Trauma. 2005;58:181-6.

\title{
Near-fatal bleeding after transmyocardial ventricle lesion during removal of the pectus bar after the Nuss procedure
}

\author{
Frank-Martin Haecker, MD, ${ }^{\mathrm{a}}$ Tobias Berberich, MD, ${ }^{\mathrm{a}}$ Johannes Mayr, MD, ${ }^{\mathrm{a}}$ and Franco Gambazzi, MD, \\ Basel, Switzerland
}

In 1998, the technique of minimally invasive repair of pectus excavatum (MIRPE) was first described by Nuss

From the Division of Pediatric Surgery, ${ }^{a}$ University Children's Hospital, and Division of Thoracic Surgery, ${ }^{\mathrm{b}}$ University Hospital, Basel, Switzerland.

Received for publication June 28, 2008; accepted for publication July 17, 2008; available ahead of print Sept 22, 2008

Address for reprints: Frank-Martin Haecker, MD, Associate Professor of Pediatric Surgery, University Children's Hospital, Department of Pediatric Surgery, PO Box, CH-4005 Basel, Switzerland (E-mail: frankmartin.haecker@ukbb.ch).

J Thorac Cardiovasc Surg 2009;138:1240-41

0022-5223/ $\$ 36.00$

Copyright $\odot 2009$ by The American Association for Thoracic Surgery doi:10.1016/j.jtcvs.2008.07.027 et al. ${ }^{1}$ This procedure is reported to be less invasive and to achieve cosmetically better results than conventional surgery, and has been introduced in many centers., ${ }^{2,3}$ Because of the widespread use of MIRPE, pediatric surgeons are faced with a new spectrum of complications. ${ }^{2-5}$ Cardiac perforation represents a rare but potentially serious condition that has to be taken into consideration when dealing with MIRPE. There are several reports of cardiac perforation during implantation of a pectus bar within the MIRPE procedure. ${ }^{2,3,5}$ However, this is the first report of a life-threatening transmyocardial ventricle lesion during removal of the bar. 


\section{CLINICAL SUMMARY}

We report on a 20-year-old woman who had undergone thoracotomy and cardiac surgery for transposition of great vessels and mild pulmonary valve stenosis (Mustard technique) at the age of 18 months. Fifteen years later, she presented with an asymmetric, deep long pectus excavatum. After comprehensive preoperative evaluation including cardiologic and psychologic counseling, MIRPE was performed. The pectus bar was directly positioned onto the rib. She had an uneventful intraoperative and postoperative course. However, on postoperative day 6 , she developed postpericardiotomy syndrome, which was treated successfully by intravenous steroids. ${ }^{4}$ Further routine follow-up visits were uneventful, and 3 years after the insertion, the removal of the bar was scheduled. Again, preoperative clinical examination and cardiologic evaluation including echocardiography was conducted and revealed no significant pathologic result. The operation was performed under general endotracheal anesthesia using a double-lumen tube. After removal of the lateral stabilizers, the bar was bent into its original straight shape, and afterward we started to remove the bar. During the preparation and loosening of the intensively adherent bar, massive bleeding along the bar occurred, requiring immediate extensive volume resuscitation. Leftsided thoracoscopy showed massive hemorrhage from the myocardium. Performing bilateral thoracotomy using the clamshell incision, we identified the bar crossing the myocardium in the anterior aspect. The pericardium was not definable. After removal of the bar, 2 right ventricular lesions as large as a fingertip could be closed successfully using monofilament felt buttressed sutures. Ongoing volume resuscitation included $25 \mathrm{U}$ of packed red blood cells (500 $\mathrm{mL}$ ), numerous platelet concentrates, and 10 fresh frozen plasmas, stabilizing hemodynamics and coagulation (a unit of fresh frozen plasma $=200 \mathrm{~mL}$ ). After inserting bilateral chest tubes and a retrosternal drain, the patient was referred to the intensive care unit in a hemodynamically stable condition. Ventilation was continued for 5 days, and on postoperative day 12 , the woman was discharged.

Today, 2 years after removal of the bar, the patient is in a good condition with the same exercise tolerance as preoperatively, and the cosmetic result is good.

\section{DISCUSSION}

After the first description of the MIRPE procedure as a safe and technically easy operation, ${ }^{1}$ subsequent reports listed a number of relevant perioperative and postoperative complications..$^{2-5}$ Even though most of the complications are minor and easily dealt with, some major complications are of concern. Cardiac complications include pericarditis $(0.4 \%$ to $5 \%)$, pericardial effusion $(0.2 \%$ to $2.4 \%)$, and postcardiotomy syndrome $(0.4 \%)$. However, life-threatening complications have included substantial bleeding or cardiac perforation. Cardiac perforation as perioperative complication $^{2,3,5}$ and massive bleeding as early and/or late complication have been reported recently. ${ }^{2}$ We add a lifethreatening complication of substantial bleeding from 2 transmyocardial lesions of the ventricle caused by the bar, which occurred during removal of the bar. We speculate that the previous episode with postcardiotomy syndrome and persistent pericarditis after the MIRPE procedure had led to extensive adhesions between the bar and the myocardium. These adhesions might have led to substantial lesions of the myocardium after removal of the bar. In addition, the situation after the Mustard procedure represents a special issue. The right ventricle, in left-ventricular function and no longer protected by the pericardium, was located directly retrosternal and therefore promoted the calcified adhesions to infiltrate the relatively thin ventricular wall.

In conclusion, substantial hemorrhage and cardiac perforation associated with the MIRPE procedure have been previously limited to episodes in the operating room at the time of insertion of the bar. This is the first report of a life-threatening transmyocardial ventricle lesion during removal of the bar. Despite the fact that the MIRPE procedure is considered a relatively simple endeavor, surgeons and patients should be aware of these elementary complications, both during and after the procedure as well as during bar removal. The indication for MIRPE must be given special consideration in patients who have had previous cardiac surgery.

\section{References}

1. Nuss D, Kelly RE, Croitoru DP, Katz ME. A 10-year review of a minimally invasive technique for the correction of pectus excavatum. J Pediatr Surg. 1998;33: 545-52.

2. Park HJ, Lee SY, Lee CS. Complications associated with the Nuss procedure: analysis of risk factors and suggested measures for prevention of complications. J Pediatr Surg. 2004;39:391-5.

3. Castellani C, Schalamon J, Saxena AK, Hoellwarth ME. Early complications of the Nuss procedure for pectus excavatum: a prospective study. Pediatr Surg Int. 2008; 24:659-66.

4. Berberich T, Haecker F-M, Kehrer B, Erb T, Guenthard J, Hammer J, et al Postcardiotomy syndrome after minimally invasive repair of pectus excavatum. J Pediatr Surg. 2004;39:E1-3.

5. Gips H, Zaitsev K, Hiss J. Cardiac perforation by a pectus bar after surgical correction of pectus excavatum: case report and review of the literature. Pediatr Surg Int. 2008;24:617-20. 